Florian Sperling

\title{
Familiennamensrecht in Deutschland und Frankreich
}

Eine Untersuchung der Rechtslage sowie namensrechtlicher Konflikte in grenzüberschreitenden Sachverhalten

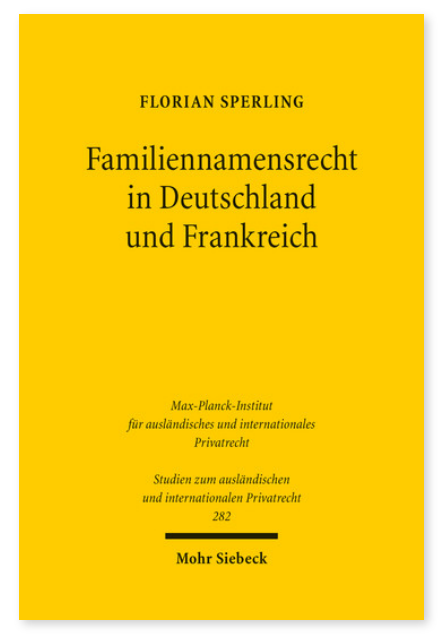

2012. XX, 226 Seiten. StudIPR 282

ISBN 978-3-16-152312-0

DOI 10.1628/978-3-16-152312-0

eBook PDF $69,00 €$

ISBN 978-3-16-152198-0

fadengeheftete Broschur 69,00€
Das Familiennamensrecht hat in den vergangenen Jahrzehnten weitreichende Veränderungen erfahren. Zuletzt wurde das Namensrecht der EU-Mitgliedstaaten zunehmend von der Rechtsprechung des EuGH geprägt. Florian Sperling vergleicht das Familiennamensrecht Deutschlands und Frankreichs und arbeitet die Unterschiede heraus. Er zeigt Konflikte auf, die in grenzüberschreitenden Sachverhalten aus der Unterschiedlichkeit der Rechtsordnungen resultieren können. Anhand konkreter Beispiele beleuchtet er insbesondere die Problematik der sogenannten »hinkenden Namensführung«. Abschließend beschäftigt er sich mit der Frage, wie die dargestellten Konflikte vermieden werden könnten. Neben der Möglichkeit einer Rechtsvereinheitlichung setzt er sich mit dem »Grunkin-Paul«-Urteil des EuGH aus dem Jahr 2008 und dem darin postulierten Prinzip der EU-weiten Anerkennung von Namen auseinander.

Florian Sperling Keine aktuellen Daten verfügbar

Jetzt bestellen:

https://mohrsiebeck.com/buch/familiennamensrecht-in-deutschland-und-frankreich-9783161523120?no_cache=1 order@mohrsiebeck.com

Telefon: +49 (0)7071-923-17

Telefax: +49(0)7071-51104 